\title{
PRODUÇÃO DE VÍDEOS AMADORES DE EXPERIMENTOS: algumas contribuições para se pensar o processo educativo
}

\author{
Wilmo Ernesto Francisco Junior ${ }^{l}$ \\ Ana Paula Aquino Benigno2
}

\section{RESUMO}

A produção de vídeos de experimentos se descortina como uma ferramenta para as atividades experimentais, permitindo entrelaçar experimento, linguagem audiovisual e a ciência química. Nesses termos, o presente trabalho investigou a produção de vídeos de experimentos por estudantes, focando especialmente as questões técnico-estéticos da produção e como estas podem se interrelacionar com o processo educativo. A análise dos vídeos demonstrou a presença espontânea de técnicas e elementos estéticos (música, dramatização, humor) que muitas vezes não se fazem presentes nas aulas de ciências. A diversão, a liberdade, a criatividade e a responsabilidade foram características que surgiram e estão ligadas ao caráter lúdico e ao engajamento pela atividade. Assim, a interação e o envolvimento dos sujeitos na produção dos vídeos possibilitam ao professor promover a discussão do conhecimento científico de maneira ampliada.

Palavras-chave: Linguagem Audiovisual. Experimentação. Tecnologias Digitais.

\section{PRODUCTION OF AMATEUR VIDEOS OF EXPERIMENTS: some contributions to}

\section{think the educative process}

\begin{abstract}
Currently, digital technologies arise as an additional tool for the inclusion of practical activities, intertwining lab work, audiovisual language and the chemical science. In this manner, this paper investigated an activity of video production by students with special focus on technical-esthetics aspects of the audiovisual materials and its influence on the educative process. Video analysis demonstrated the spontaneous inclusion of techniques and esthetic elements (such as music, dramatization, and humor) seldom considered in science classes. Fun, freedom, creativity and responsibility were characteristics that emerged and which are associated to a

1 Doutor em Química/Educação Química (Instituto de Química de Araraqura/UNESP). Professor da Universidade Federal de Alagoas/UFAL, Campus de Arapiraca e do Programa de Pós-Graduação em Ensino de Ciências e Matemática/PPGECIM/UFAL. E-mail: wilmojr@bol.com.br

2 Mestre em Ensino de Ciências e Matemática (PPGECIM/UFAL). Professora do Instituto Federal do Ceará, Campus Umirim. E-mail: apbenigno@yahoo.com.br
\end{abstract}


playful environment and to the engagement with the activity. Thus, the interaction and the students' involvement in the video production may allow promoting the discussion of scientific knowledge in a wider way.

Keywords: Audiovisual language. Lab work. Digital Technologies.

\title{
PRODUCCIÓN DE VÍDEOS AFICIONADOS DE EXPERIMENTOS: algunas contribuiciones para pensar el proceso educativo
}

\begin{abstract}
RESUMEN
La producción de vídeos de experimentos se devela como una herramienta para las actividades experimentales, permitiendo entrelazar experimento, lenguaje audiovisual y la ciencia química. En este sentido, el presente trabajo investigó la producción de vídeos de experimentos por parte de estudiantes, enfocando especialmente las cuestiones técnico-estéticas de la producción y cómo éstas pueden interrelacionarse con el proceso educativo. El análisis de los vídeos demostró la presencia espontánea de técnicas y elementos estéticos (música, dramatización, humor) que a menudo no se hacen presentes en las clases de ciencias. La diversión, la libertad, la creatividad y la responsabilidad fueron características presentes y están ligadas al carácter lúdico y al compromiso por la actividad. Así, la interacción y la participación de los sujetos en la producción de los vídeos posibilitan al profesor promover la discusión del conocimiento científico de manera ampliada.
\end{abstract}

Palabras clave: Lenguaje Audiovisual. Actividades Prácticas. Tecnologías Digitales.

\section{INTRODUÇÃO}

Não de hoje a experimentação é apontada como elemento fulcral para o ensino de ciências (HODSON, 1994; HEID; SHAH, 2007). Ao mesmo tempo, a simples inclusão de atividades experimentais não é suficiente para efetivar a aprendizagem. É fundamental a concatenação do trabalho prático com a discussão, análise, interpretação, interação social, validação social e comunicação dos resultados, elementos que configuram os modos de fazer ciência, seu processo e produtos, operando no âmbito da apropriação da linguagem como mediadora do aprender ciências (MORTIMER; SCOTT, 2003; HOFSTEIN et al, 2005).

Nessa perspectiva, a produção de vídeos amadores de experimentos é uma possibilidade adicional para a inserção da experimentação, sobretudo a partir do advento das tecnologias digitais (LICHTER, 2012; FRANCISCO JUNIOR, 2017). A produção de vídeos pode ser considerada 
ferramenta importante para aproximação ao cotidiano e às diversas linguagens, bem como para o estudo de situações-problema. Moran et al. (2013) destacam que a produção de vídeos possibilita integrar linguagens e manipular a realidade espaço-temporal. Para os autores, com a minituarização da câmera, a produção de vídeos adquiriu uma nova dimensão, mais moderna e lúdica que permite aos estudantes brincarem com a realidade em diversos espaços.

Nessa perspectiva, a produção de vídeos amadores é um jogo em que os estudantes assumem o papel de roteiristas, produtores, diretores, narradores e atores. Ao alinhavar características como liberdade, criatividade e responsabilidade pelo ato de aprendizado, emerge a ludicidade da ação educativa. Ao estimular a criação, permitindo liberdade de agir no desenvolvimento da atividade, a produção auviovisual possibilita ao aprendiz engajamento em sua consecução (DOHME, 2003). Ainda sobre isso, Chateau (1987) assinala que o aspecto criador de um jogo lou atividade lúdica) promove um distanciamento que leva os sujeitos a um plano no qual eles têm o poder da representação com base nas várias simulações e fantasias que executa por meio da atividade realizada. Esse distanciamento, que é voluntário, permite a liberdade e a criatividade para criar.

Além da produção do material audiovisual, há possibilidade do professor utilizá-lo para discutir, problematizar, comentar e aprofundar os múltiplos sentidos e valores que cada vídeo pode trazer para o cotidiano escolar. Dessa forma, o vídeo não seria o fim, mas uma ferramenta que conduz a um processo de integração de linguagens e conteúdos, resultando em possibilidades da ação lúdica para a apropriação do conhecimento, pois, mais importante do que o produto (vídeo produzido), é a relação entre o produto e o processo de sua construção, isto é, entre a produção do vídeo e do conhecimento.

Tal relação entre o produto e o processo de produção remete à possibilidade de construção do conhecimento. Assumindo uma perspectiva freiriana, aprender é um processo que deve possibilitar ao aprendiz uma 
curiosidade crescente, tornando-o, cada vez mais, criador. A capacidade de aprender, quanto mais criticamente ocorre, colabora na construção e desenvolvimento de uma curiosidade metodicamente rigorosa - a curiosidade epistemológica. Assim, "Aprender é uma aventura criadora, é construir, reconstruir, constatar para mudar, o que não se faz sem abertura ao risco e à aventura do espírito" (FREIRE, 2009, p. 69).

A produção audiovisual corresponderia então a um momento de envolvimento cognitivo dos sujeitos, no qual curiosidade, criatividade e liberdade de ação são fundamentais. Estas se relacionam diretamente com o envolvimento cognitivo dos sujeitos. Isto é, para produzir é indispensável que o sujeito esteja disposto a aprender.

Nesse cenário, o presente trabalho teve como objetivo analisar uma atividade de produção de vídeos amadores de experimentos, tendo como principal indagação: que elementos podem ser úteis para se pensar a produção dos vídeos amadores como processo educativo?

\section{PROCEDIMENTOS METODOLÓGICOS}

\section{Contexto da pesquisa}

O presente estudo é de natureza qualitativa e se enquadra nos moldes de um estudo de caso, em que um contexto ou acontecimento específico é investigado detalhadamente, no sentido de se avaliar descritivamente a situação (YIN, 1984). Para Yin (1984, p.14), uma característica geral de um estudo de caso é o "desejo de compreender fenômenos sociais complexos" que "retém as características significativas e holísticas de eventos da vida real". O caso investigado (considerado um fenômeno social complexo com características da vida real) foi uma proposta didático-pedagógica de produção de vídeos de experimentos, realizada com uma turma de estudantes do $2^{\circ}$ ano do Ensino Médio do Instituto Federal de Alagoas, em um Campus do interior do Estado.

Inicialmente, a proposta de produção de vídeos de experimentos foi apresentada pela professora (também autora deste trabalho) como uma das atividades de avaliação bimestral parcial, havendo consulta sobre o 
interesse e a anvência dos estudantes em participar. A aceitação por parte dos estudantes foi unânime. A pesquisa foi conduzida no ano letivo de 2012 , com 19 estudantes, sendo 11 do sexo feminino e 8 do sexo masculino, todos dentro da faixa etária regular para o Ensino Médio brasileiro.

Para o desenvolvimento das atividades a turma foi dividida 4 grupos. $O$ assunto escolhido para a produção do vídeo foi oxidação-redução, tema que se encontrava em estudo no momento da proposição da atividade. Para a realização das atividades não foram apresentados/fornecidos roteiros ou informações, seja para a produção audiovisual ou para os experimentos, caracterizando liberdade irrestrita de produção, à exceção da temática. Entretanto, salienta-se que foram fornecidas informações sobre fontes de experimentos (livros, páginas da internet e periódicos) para auxiliar 0 trabalho.

Os estudantes tiveram um tempo de 3 semanas para a produção. Neste tempo deveriam escolher o experimento e apresentá-lo à professora no intuito de se avaliar periculosidade e descarte de materiais. Ao final da produção, cada grupo exibiu os vídeos aos demais colegas, caracterizando um momento de discussão com a turma, tendo como foco o conteúdo abordado.

\section{Análise e discussão dos dados}

Como fonte de dados para a presente pesquisa foram empregados os vídeos produzidos, os quais foram submetidos à análise fílmica. Vanoye e Goliot-Lété (2013) destacam que a análise fílmica não se configura um fim em si, sendo uma prática procedida de um pedido, por sua vez situado em um contexto institucional variável que resulta em demandas variáveis. De tal forma: "A definição do contexto e do produto final é, portanto, indispensável ao enquadramento da análise. Permite esboçar (...) seus limites, suas formas e seus suportes, seu ou seus eixos" (VANOYE; GOLIOT-LÉTÉ, 2009, p. 9-10).

Para a análise de um filme ou vídeo é necessário se atentar e distinguir duas diferentes etapas da análise: a desconstrução e a reconstrução. Basicamente, a desconstrução equivale à descrição, enquanto a 
reconstrução concerne à interpretação, num movimento em direção ao próprio filme.

\begin{abstract}
Analisar um filme ou um fragmento é [...] decompô-lo em seus elementos constitutivos. É despedaçar, descosturar, desunir, extrair, separar, destacar e denominar materiais que não se percebem isoladamente 'a olho nu' [...]. Uma segunda fase consiste, em seguida, em estabelecer elos entre esses elementos isolados, em compreender como eles se associam [...] (VANOYE; GOLIOT-LÉTÉ, 2009, p. 14-15).
\end{abstract}

Os mesmos autores apresentam uma proposta que compreende sete aspectos para a descrição de um filme: 1) Numeração do plano; 2) Elementos visuais representados; 3) Escala dos planos (lugar da câmera em relação ao plano), incidência angular (tomada frontal/lateral), profundidade de campo (iluminação, disposição de objetos, o lugar da câmera); 4) Movimento (no campo, dos atores, da câmera; 5) "Raccords" passagens de um plano a outro (olhares, movimentos, cortes, fusões, escurecimento, outros efeitos); 6) Trilha sonora; 7) Relações sons/imagens.

A perspectiva de análise adotada igualmente considera a complexidade de sentidos que podem ser produzidos com o vídeo, supondo circularidade entre produção e recepção, em que o produtor pode buscar uma decodificação mais específica (o significado preferencial) supondo um determinado público (endereçamento), ao passo que o receptor pode empreender uma nova interpretação (leitura preferencial). Neste trabalho foram focados o significado preferencial e o endereçamento. $O$ primeiro está associado ao interesse e a mensagem pensada pelos autores do vídeo. Assim, o significado preferencial é aquele determinado pelos sujeitos que detêm o poder da produção da obra, influenciados por diferentes aspectos, como suas visões de mundo, escolhas estéticas, experiências prévias.

O endereçamento tem relação com o público espectador e, principalmente, em imaginar o modo como este efetuará a leitura do material audiovisual. Consciente ou inconscientemente, os produtores escolhem e ajustam aquilo que aparecerá ou não no vídeo pensando em quem o assistirá. Isto é, os autores supõem um espectador e uma maneira pela qual o vídeo pode ser compreendido. Logo, o endereçamento diz 
respeito à relação filme-espectador pensada pelos produtores (ELLSWORTH, 2001). Por tal razão, mecanismos podem ser inseridos no filme de modo a privilegiar uma dada leitura (ELLSWORTH, 2001).

Assumindo a insuficiência de uma análise que retrata somente o produto final, deve-se considerar a investigação do processo de produção. Como forma de triangulação dos dados, os estudantes participantes responderam individualmente um questionário (Quadro 1) cujo intuito foi levantar informações sobre a escolha dos experimentos, aspectos positivos e negativos, além das dificuldades.

QUADRO 1 - Questões respondidas pelos estudantes sobre a produção dos vídeos.

1. Explique como foi a seleção pelo grupo do experimento para a produção do vídeo. Por que escolheram esse experimento?

2. Do você gostou na produção do vídeo do experimento? Do você não gostou na produção do vídeo do experimento?

3. Aponte as dificuldades encontradas durante a produção do vídeo.

Fonte: Os autores.

A apreciação das informações originárias dos questionários teve como suporte a análise de conteúdo (BARDIN, 2006). Os dados escritos foram lidos repetidamente, caracterizando uma leitura flutuante, em que as primeiras impressões são captadas e se tornam mais precisas conforme os objetivos da pesquisa (BARDIN, 2006). Os resultados foram discutidos em comparação à análise fílmica do significado preferencial e endereçamento. Para a discussão dos resultados foram empregados referenciais sobre ludicidade, a perspectiva crítica de Freire sobre o conhecimento e trabalhos já produzidos acerca da produção de audiovisual no ensino de ciências.

\section{RESULTADOS E DISCUSSÃO}

Ao total foram produzidos quatro vídeos na atividade. Os títulos originais, uma breve descrição do experimento proposto, bem como o número de estudantes produtores são apresentados pela Tabela 1. 
TABELA 1 - Experimentos apresentados para cada vídeo.

\begin{tabular}{|c|c|c|c|c|}
\hline Vídeo & Duração & $\begin{array}{l}\text { Ambiente de } \\
\text { filmagem }\end{array}$ & Áudio & Imagens \\
\hline 1 & $1 \mathrm{~m} 34 \mathrm{~s}$ & $\begin{array}{l}\text { Doméstico (filmado } \\
\text { na casa dos } \\
\text { integrantes). }\end{array}$ & $\begin{array}{l}\text { Áudio ambiente, } \\
\text { sem narração e } \\
\text { com inserção de } \\
\text { trilha sonora. }\end{array}$ & $\begin{array}{l}\text { Imagens ambiente } \\
\text { conjugadas às legendas. } \\
\text { Os estudantes não apare- } \\
\text { cem durante as imagens. }\end{array}$ \\
\hline 2 & $11 \mathrm{m02s}$ & $\begin{array}{l}\text { Escolar (sala de } \\
\text { informática, labo- } \\
\text { ratório) e entorno } \\
\text { externo da escola. }\end{array}$ & $\begin{array}{l}\text { Áudio ambiente, } \\
\text { narração com- } \\
\text { partilhada entre } \\
\text { os estudantes. }\end{array}$ & $\begin{array}{l}\text { Imagens ambiente. Os } \\
\text { estudantes são } \\
\text { apresentadores. Sem } \\
\text { legendas. Créditos finais. }\end{array}$ \\
\hline 3 & $3 m 35 s$ & \begin{tabular}{l}
\multicolumn{2}{c}{ Doméstico } \\
(filmado na casa \\
de um dos \\
participantes).
\end{tabular} & $\begin{array}{l}\text { Áudio ambiente, } \\
\text { narração com- } \\
\text { partilhada entre } \\
\text { os estudantes. }\end{array}$ & $\begin{array}{l}\text { Prevalecem imagens } \\
\text { ambiente. Créditos finais. }\end{array}$ \\
\hline 4 & $4 \mathrm{~min} 39 \mathrm{~s}$ & $\begin{array}{l}\text { Escolar (filmado em } \\
\text { sala de aula). }\end{array}$ & $\begin{array}{l}\text { Áudio ambiente, } \\
\text { narração inter- } \\
\text { calada entre os } \\
\text { apresentadores. }\end{array}$ & $\begin{array}{l}\text { Prevalece imagens } \\
\text { ambiente conjugadas à } \\
\text { narração. }\end{array}$ \\
\hline
\end{tabular}

Fonte: Os autores.

A duração dos vídeos apresentou pouca uniformidade (Tabela 2), o que pode ser atribuído à inserção de elementos estético-culturais variados. O vídeo de maior duração abarcou questões sociais em maior amplitude, fator que elevou o tempo.

TABELA 2 - Duração, contexto da filmagem e características técnicas (áudio e imagens) dos vídeos produzidos.

\begin{tabular}{|c|c|c|c|c|}
\hline Vídeo & Duração & $\begin{array}{l}\text { Ambiente de } \\
\text { filmagem }\end{array}$ & Áudio & Imagens \\
\hline 1 & $1 \mathrm{~m} 34 \mathrm{~s}$ & $\begin{array}{l}\text { Doméstico (filmado } \\
\text { na casa dos } \\
\text { integrantes). }\end{array}$ & $\begin{array}{l}\text { Áudio ambiente, } \\
\text { sem narração e } \\
\text { com inserção de } \\
\text { trilha sonora. }\end{array}$ & $\begin{array}{l}\text { Imagens ambiente } \\
\text { conjugadas às legendas. } \\
\text { Os estudantes não apare- } \\
\text { cem durante as imagens. }\end{array}$ \\
\hline 2 & $11 \mathrm{m02s}$ & $\begin{array}{l}\text { Escolar } \\
\text { (sala de informática, } \\
\text { labo-ratório) e }\end{array}$ & $\begin{array}{l}\text { Áudio ambiente, } \\
\text { narração com- } \\
\text { partilhada entre }\end{array}$ & $\begin{array}{lr}\text { Imagens ambiente. } & \text { Os } \\
\text { estudantes } & \text { são } \\
\text { apresentadores. } & \text { Sem }\end{array}$ \\
\hline
\end{tabular}




\begin{tabular}{|c|c|c|c|c|}
\hline & & $\begin{array}{l}\text { entorno externo da } \\
\text { escola. }\end{array}$ & os estudantes. & legendas. Créditos finais. \\
\hline 3 & $3 m 35 s$ & $\begin{array}{l}\text { Doméstico (filmado } \\
\text { na casa de um dos } \\
\text { participantes). }\end{array}$ & $\begin{array}{l}\text { Áudio ambiente, } \\
\text { narração com- } \\
\text { partilhada entre } \\
\text { os estudantes. }\end{array}$ & $\begin{array}{l}\text { Prevalecem imagens } \\
\text { ambiente. Créditos finais. }\end{array}$ \\
\hline 4 & $4 \min 39 s$ & $\begin{array}{l}\text { Escolar (filmado em } \\
\text { sala de aula). }\end{array}$ & $\begin{array}{l}\text { Áudio ambiente, } \\
\text { narração inter- } \\
\text { calada entre os } \\
\text { apresentadores. }\end{array}$ & $\begin{array}{l}\text { Prevalece imagens } \\
\text { ambiente conjugadas à } \\
\text { narração. }\end{array}$ \\
\hline
\end{tabular}

Fonte: Os autores.

Já os vídeos mais preocupados com a dimensão instrumental (experimento) tiveram menor duração. No que concerne ao contexto de filmagem, notou-se variabilidade entre ambiente doméstico, escolar e ambientes externos (Tabela 2).

Em apenas um caso (vídeo 2) houve alternância de ambientes na mesma produção. Neste vídeo, os estudantes iniciam com um cenário de telejornal (ambiente interno - laboratório de informática), passam por ambiente externo (entorno da escola) e finalizam com a filmagem do experimento no laboratório didático da escola.

A relação entre as sequências de filmagem (Figura 1) em ambiente interno e externo permitiram a construção de um enredo de telejornal, mas, que ao mesmo tempo, não perde o foco do experimento, que funciona como o clímax da produção.

FIGURA 1 - Variação do ambiente de filmagem do vídeo 2.
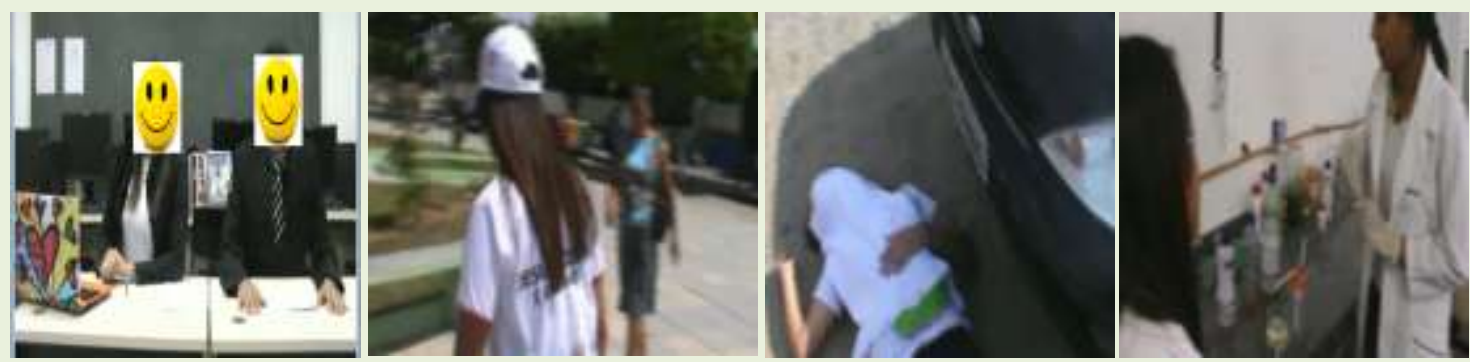

Fonte: Os autores.

Neste vídeo nota-se um diálogo mais aberto, influenciando especialmente o endereçamento. Por sua vez, nos demais vídeos não há um 
enredo fora da atividade experimental, implicando em foco no experimento e praticamente ausência de uma dimensão social da química.

Para a realização do experimento prevaleceu um ambiente de laboratório alternativo (doméstico - vídeo 1 e 3; sala de aula - vídeo 4). Em uma única situação o experimento foi filmado no laboratório escolar. A discussão acerca de um ambiente específico e com condições adequadas para as práticas experimentais versus os espaços alternativos é bastante ampla. Indubitavelmente, a presença de laboratórios escolares para aulas experimentais é uma defesa inconteste para o provimento de melhorias na educação em química. Ao mesmo tempo, conforme aponta Hodson (1994), é preciso recontextualizar o trabalho experimental.

Deste modo, é importante que o trabalho experimental se constitua em momentos para que o educando possa agir, refletir e interagir socialmente, não bastando apenas envolvê-los na realização da atividade experimental e/ou na manipulação de materiais. É fundamental concatenar o trabalho prático com a discussão, análise, interpretação, validação social e comunicação dos resultados alcançados, elementos que integram os modos de fazer ciência, seu processo e produtos, operando no âmbito da apropriação da linguagem como mediadora do aprender ciências (MORTIMER; SCOTT, 2003). Portanto, mais importante do que o espaço de realização do experimento são as atividades que dele podem decorrer. Ainda que não fisicamente, os vídeos ampliam as possibilidades da prática experimental, conjugando diferentes espaços físicos e temporalidades, podendo funcionar como ferramenta de estudo para os produtores e para os colegas.

Quanto ao áudio dos vídeos, de maneira geral prevalece o som captado no momento das filmagens, provavelmente em função da maior facilidade técnica, uma vez que não é exigido trabalho de edição posterior ajuste de imagem e som. Em três vídeos a narração é realizada pelos estudantes durante a própria captura das imagens (narrador-imagemimagem). A inserção do áudio de narração após captura das imagens não foi verificada. Em um dos vídeos não há narração, sendo utilizadas legendas

Revista Exitus, Santarém/PA, Vol. 8, № 2, p. 244 - 272, MAI/AGO 2018. 
que acompanham as imagens. Neste também há uma música que acompanha todo o vídeo. A inserção de outras imagens que não as captadas pelos estudantes foi verificada em um único caso (vídeo 2).

Não obstante o uso de alguns recursos de edição, tais como legendas, trechos de outros vídeos, trilha sonora e créditos (Tabela 2), as produções audiovisuais em geral apresentaram baixa qualidade técnica. Isso é corroborado por algumas características como imagens trêmulas, imagens fora de foco, interferência de sons externos (ruídos) e sons cortados antes da finalização de falas. Tais aspectos técnicos remontam às condições de produção do vídeo. Nesse sentido, dois fatores parecem ter relevância. O primeiro refere-se à falta de orientações técnicas específicas sobre produção audiovisual. A discussão de temas como a roteirização, captação de imagens, sons e uso de programas de edição poderiam auxiliar nessa direção.

O segundo fator estaria associado à própria importância dada à produção de um vídeo sobre experimentos químicos, cujo foco estaria na realização do experimento, em detrimento ao produto audiovisual. Tal preocupação pode ser percebida ao se analisar o tempo de cada vídeo destinado à exposição instrumental (materiais e procedimentos), em relação ao tempo destinado a outros assuntos ou à exposição conceitual (Tabela 3). Pereira et al (2011), analisando vídeo que também apresentaram problemas de qualidade técnica, identificaram igualmente que o tempo referente à parte experimental é relativamente superior, reforçando a priorização da atividade experimental. Contudo, vale destacar que os estudantes não são profissionais da produção audiovisual. Ademais, não se pode perder de vista que os objetivos da produção eram didáticos e não exigia cuidados pormenorizados com a dimensão técnica. 
TABELA 3 - Recursos estéticos, tempo de exposição sobre assuntos diversos e de exposição instrumental.

\begin{tabular}{|c|c|c|c|c|}
\hline Vídeo & Recursos estéticos & $\begin{array}{l}\text { Tempo de exposição } \\
\text { sobre assuntos diversos }\end{array}$ & $\begin{array}{l}\text { Tempo de } \\
\text { exposição } \\
\text { instrumental }\end{array}$ & $\begin{array}{l}\text { Tempo de } \\
\text { exposição } \\
\text { conceitual }\end{array}$ \\
\hline 1 & $\begin{array}{ll}\text { Música } & e \\
\text { legendas/texto } & \end{array}$ & $15 \mathrm{seg}$ & $1 \mathrm{~min} 19 \mathrm{seg}$ & $20 \mathrm{seg}$ \\
\hline 2 & $\begin{array}{l}\text { Dramatização, } \\
\text { animação, figurino } \\
\text { e música }\end{array}$ & $7 \mathrm{~m} 31 \mathrm{seg}$ & $3 \min 30$ seg & $15 \mathrm{seg}$ \\
\hline 3 & $\begin{array}{l}\text { Dramatização, } \\
\text { figurino (fantoches) }\end{array}$ & $1 \mathrm{~min} 33 \mathrm{seg}$ & $2 \min 02 s e g$ & $32 \mathrm{seg}$ \\
\hline 4 & Animação & $1 \mathrm{~min} 10 \mathrm{seg}$ & $3 \mathrm{~min} 29 \mathrm{seg}$ & $0 \mathrm{seg}$ \\
\hline
\end{tabular}

Fonte: Os autores.

A preocupação instrumental e o fato dos vídeos apresentarem características amadoras não limitaram, por outro lado, a criatividade e a inserção de aspectos estético-culturais, cuja presença foi observada espontaneamente em todas as produções (Tabela 3), demonstrando que tais elementos são vistos como necessários para melhor se expressarem por meio do audiovisual. Para Ferrés (1996), a produção de vídeos permite aos estudantes descobrir novas possibilidades de expressão, em um esforço de criação coletiva quer permite experimentar e experimentar-se.

Tal criatividade, por sua vez, necessita de liberdade, esta proporcionada pela manifestação artística no momento do improviso. Freire corrobora a ideia de criatividade necessária à prática transformadora, da qual emerge também o caráter político da educação.

Essa compreensão me ensinou que a criatividade precisava de liberdade. (...). Isto foi um fundamento, também, para que eu soubesse, depois, como a criatividade na pedagogia está relacionada à criatividade na política. Uma pedagogia autoritária, ou um regime político autoritário, não permite a liberdade necessária à criatividade, e é preciso criatividade para se aprender (FREIRE; SHOR, 2008, p. 31). 
É importante assinalar que os recursos técnicos estão relacionados a dimensões estéticas e culturais, as quais foram espontaneamente empregadas e enriquecem os vídeos. Tal fato indica que os estudantes os consideram necessários como elementos que configuram a forma (livre) de se expressarem. Em outro estudo que fez uso da produção de vídeos de experimentos, Pereira et al (2011) argumentam que isso pode estar associado à legitimação do vídeo como ferramenta da cultura dos estudantes e nem tanto como estratégia de ensino.

Toda expressão artística, e pode-se assim considerar a livre produção audiovisual, carrega em si as singularidades e experiências anteriores dos autores durante o processo de criação. Considerando que o vídeo é uma manifestação alinhavada à própria compreensão dos sujeitos a respeito dos vídeos e a forma como veem a ciência, suas produções carregam indícios daquilo que consideram importantes para a expressão audiovisual e para a educação científica. Consequentemente, a presença de elementos variados como música, encenação e dramatização torna-se relevante, uma vez que estes raramente se fazem presentes em aulas de ciências. Além disso, o próprio experimento assume, em alguns casos, uma dimensão estética que pode ser relevante, pautando, por vezes, a escolha dos experimentos.

Nota-se, portanto, uma conjugação entre ciência, aspectos estéticoculturais, além de humor e emoção, cuja inserção em aulas de química/ciência poderiam reverberar em resultados positivos. Para Moran ( $p$. 19): "A construção do conhecimento, a partir do processamento multimidiático, é mais livre, menos rígida, com conexões mais abertas, que passam pelo sensorial, pelo emocional e pela organização do racional (...)". Assumindo a ciência como produção cultural humana, por conseguinte, também marcada pelas conexões sensoriais, emocionais e racionais, a produção audiovisual integra aspectos relevantes para a formação científico-cultural. Assim, o vídeo configura-se como o "lugar" para que os sujeitos dialoguem, sendo o diálogo o ponto de acesso à cultura. 
FIGURA 2 - Imagem da abertura do vídeo e dos estudantes na bancada de apresentação do jornal.

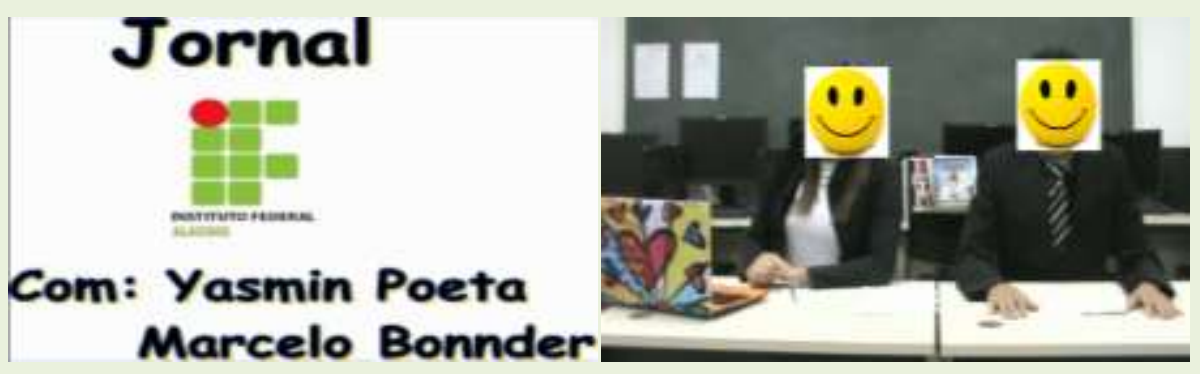

Fonte: Os autores.

Tal característica emergiu em diferentes dimensões nos vídeos produzidos. A mais marcante se deu para o vídeo apresentado no formato de telejornal (Figura 2). Este vídeo foi o único a inserir questões sociais em sua produção, não se limitando a apresentação de um experimento sobre oxidação-redução. O vídeo inicia-se com a abertura do seriado de TV estado-unidense "The big bang theory". Na sequência, é introduzida a vinheta sonora do "Jornal Nacional" e há referência a seus apresentadores (na época da produção), parodiando-se seus sobrenomes: Poeta e Bonnder.

No primeiro plano do vídeo, filmado frontalmente no laboratório de informática e com a câmera na mão, os apresentadores fazem críticas sociais concernentes ao seu entorno social, como a ausência de aulas práticas nos cursos técnicos da instituição, atrasos em construções do Campus, atraso no recebimento de auxílio transporte, além de citar eventos ocorridos na região. Há aproximações da câmera para focar os apresentadores.

Em seguida há mudança no ambiente de filmagem para local externo à escola. A mesma estudante apresentadora interpreta agora a repórter que relata uma visita técnica dos estudantes. Novamente no "estúdio" do telejornal, os apresentadores chamam uma notícia sobre um acidente de trânsito ocasionado em função do consumo de álcool pelo condutor do veículo. Filmado também em ambiente externo, um estudante interpreta um repórter que entrevista um agente policial acerca dos procedimentos legais nesta situação (Figura 3). 
FIGURA 3 - Passagens do vídeo com filmagem em ambiente externo e realização do experimento no laboratório

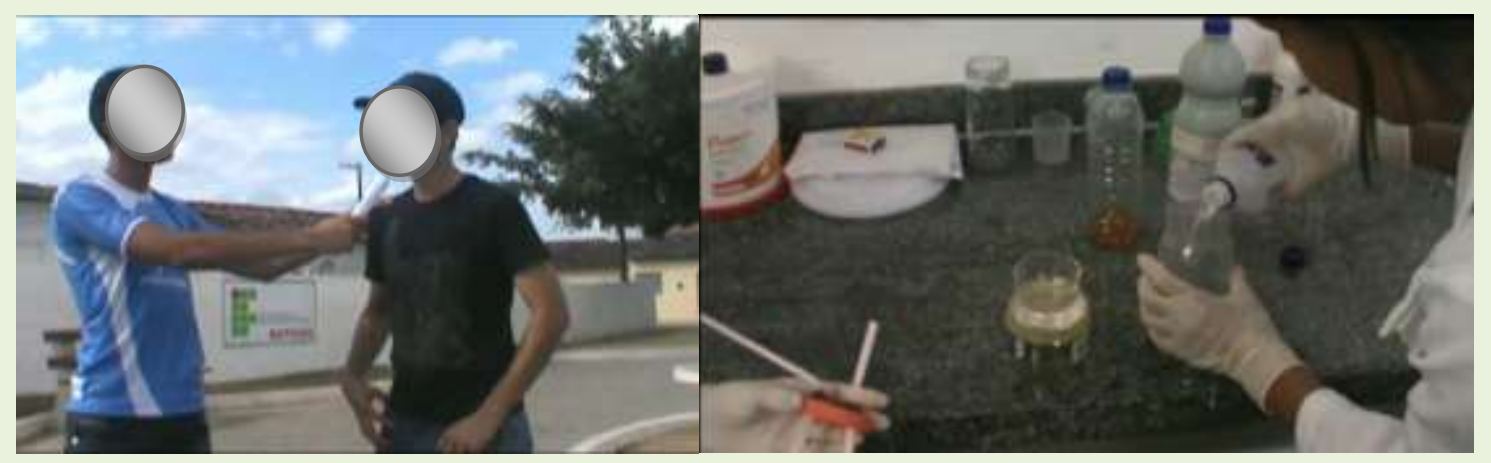

Fonte: Os autores.

Após, uma repórter vai ao laboratório de química, no qual o experimento é realizado e há uma entrevista com uma profissional da área sobre o princípio químico do bafômetro.

É possível depreender que embora haja a preocupação com a dimensão instrumental, a dimensão sócio-cultural prevalece no vídeo, inclusive com a criação de uma situação para a introdução dos aspectos químicos. Tal preocupação foi corroborada pelos dados dos questionários, a partir do qual os integrantes do grupo manifestaram a importância deste contexto social quando questionados sobre a escolha do experimento.

"Além de acharmos interessante, um dos grandes temas da atualidade é a lei seca" (Aluno 2, grupo 2).

"Oportunidade de relacionar a química com o nosso dia-adia" (Aluno 2, grupo 2).

"Gostei - Foi ótimo pois teve uma grande relação com o dia-adia" (Aluno 3, grupo 2).

A perspectiva de poder relacionar o objeto de estudo com seu dia-adia, assim como a liberdade de manisfetarem posicionamento sociais refletem a leitura de mundo dos produtores à medida que assumem sua produção. Na perspectiva freiriana, o contexto, real e concreto, não pode ser prescindido para a efetivação do processo educativo. 
E a experiência de compreensão será tão ou mais profunda quanto sejamos nela capazes de associar, jamais dicotomizar, os conceitos emergentes na experiência escolar aos que resultam do mundo da cotidianidade. Um exercício crítico sempre exigido pela leitura e necessariamente pela escuta é o de como nos darmos facilmente à passagem da experiência sensorial que caracteriza a cotidianidade à generalização que se opera na linguagem escolar e desta ao concreto tangível (FREIRE, p. 30, 2008).

O produto audiovisual é a percepção da cotidianidade dos produtores, criando possibilidades de os estudantes manifestarem sua leitura de mundo, aspecto premente para que se construam criticamente. $O$ público ao qual o vídeo se destina (endereçamento) provavelmente são os colegas de escola, uma vez que os eventos trazidos nos vídeos remetem a aspectos da vida escolar (visita ao museu, atraso nas obras, problemas com o passe escolar). A criação do vídeo, dentro desse cenário, emerge como possibilidade de integração e discussão da experiência concreta, sensorial, para a abstração e generalização, características do conhecimento escolar e científico. Em outras palavras, provoca naqueles que assistem ao vídeo a leitura da leitura anterior de mundo.

Em termos do significado preferencial este talvez seja o vídeo de maior complexidade, o que é corroborado pelas respostas dos estudantes sobre o que gostaram ao produzir o vídeo.

\footnotetext{
"Gostei de saber mais um pouco sobre o tema e como é possível devido a mudança das cores observar a presença de álcool no sangue" (Aluno 1, grupo 2).

"Gostei da criatividade desse elenco maravilhoso, do esforço de cada um e da união do grupo" (Aluno 2, grupo 2).

"Gostei muito da criatividade, destacando lógico o fato do incentivar o aprendizado dos alunos, uma vez que tornou-se uma atividade divertida e educativa" (Aluno 4, grupo 2).
}

Enquanto um dos estudantes destaca elementos da ludicidade (criatividade, compromisso) o outro elenca aspectos relacionados ao conhecimento químico, foco da atividade. Além da questão social dos riscos da bebida e dos problemas enfrentados no Campus, pode-se inferir que 
outra mensagem do vídeo é o foco educativo, de incentivo à aprendizagem.

As respostas aos questionários permitem igualmente inferir a presença da responsabilidade lúdica, que segundo Soares (2013), é uma característica que torna todos os sujeitos envolvidos na ação lúdica corresponsáveis pelo processo de ensino e aprendizagem. Tal ação lúdica não se restringiu ao produto (vídeo), mas abarca todo processo de construção, podendo envolver os estudantes-produtores em pesar desde a seleção do experimento, o formato de apresentação, o contexto do fenômeno, bem como, as (tentativas de) explicações químicas. As características de ludicidade foram verificadas em todos os vídeos.

Também empregando a dramatização como recurso técnico-estético, no vídeo 3 os estudantes empregaram fantoches para a apresentação do experimento. O vídeo é iniciado com um plano dos bonecos em que a legenda e cartaz ao fundo indicam que se tratava de um trabalho escolar (Figura 4). A câmera é posicionada de forma fixa e frontal em todo o vídeo.

FIGURA 4 - Imagens de abertura do vídeo 3.

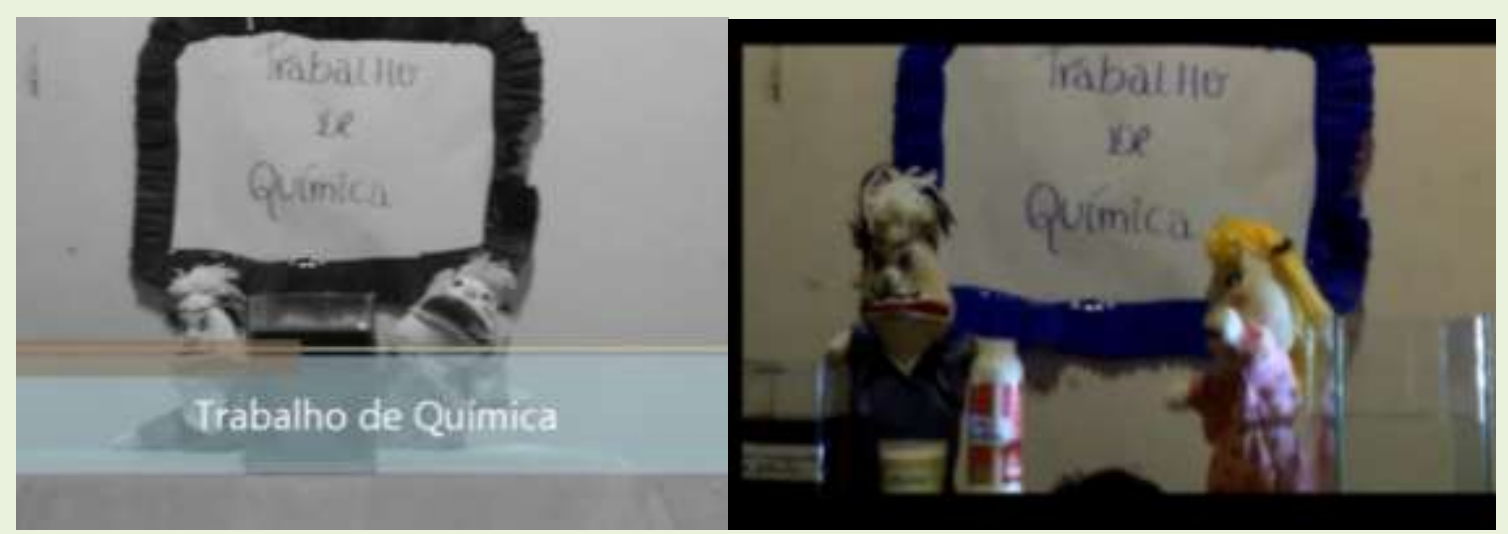

Fonte: Os autores.

Os fantoches representam um estudante (que precisa desenvolver um trabalho sobre óxido-redução) e o seu professor. Por meio de encenação com os fantoches, o vídeo descrive os materiais, as alterações ocorridas e sua interpretação sob o ponto de vista químico. Um diálogo entre o professor e a aluna destaca a simplicidade do experimento. Ao fim, fotos dos 
participantes, dos bonecos (coloridas e em preto e branco) e dos experimentos são apresentadas com recursos de animação (rolagem na vertical e horizontal, zoom de cima para baixo, de baixo para cima e lateralmente), seguido dos créditos.

A preocupação em destacar, tanto na imagem quanto na fala das personagens, que se trata de um trabalho escolar, permite depreender que o vídeo foi endereçado à professora. Contudo, também nota-se um deslocamento da perspectiva de produção do vídeo como atividade meramente avaliativa, o que é marcado pelo humor e pelo emprego de fantoches que se dirigem a um público. Dessa forma o endereçamento parece abarcar não somente a professora, mas outros estudantes de mesma faixa etária, com um destaque para a ludicidade. Tal aspecto é evidenciado pelo fato de um dos fantoches ser o professor de química e pela alternância entre o didatismo e o humor.

A liberdade de criação, típica das expressões artísticas pode, dessa forma, atuar positivamente na criatividade e nas relações de humor produzidas. A prática pedagógica sem humor e sem emoção corre um sério risco de ser enfadonha e sem sentimento. Freire e Shor (2008, p. 193-194) assinalam que:

[...] os professores podem se beneficiar de seminários de teatro, voz, movimento e comédia. Não que esses exercícios dramáticos vão transformar os professores em homens e mulheres novos, mas sim porque os talentos cômicos e criativos são demais ignorados. Não são considerados de forma séria como recursos de ensino. Talvez os seminários de teatro possam pôr pra fora a criatividade latente. Um professor que não é criativo pode liderar uma classe dialógica criativa?

Tônica similar foi identificada no vídeo "A construção de uma pilha de limão". Os estudantes se dividiram na apresentação, iniciando o vídeo com a explicitação do seu objetivo: "Olá pessoal! Agora iremos demonstrar uma experiência de óxido-redução". Neste plano aparecem todos os estudantes participantes da cintura para cima. Na sequência há um corte para o plano da mesa onde se encontram os materiais para o experimento. A câmera se desloca verticalmente para cima e mostra um dos estudantes que apresenta 
a situação prática do experimento: "Vamos fazer uma calculadora funcionar com dois limões, quatro moedinhas de cinco centavos e quatro pedaços de zinco". Com outra mudança do plano, o vídeo prossegue com a apresentação das equações químicas, sem uso de áudio, sendo a tela uma espécie de "lousa". O tempo de exposição conceitual é de 1 min21s.

Em seguida, são relatados e demonstrados os procedimentos experimentais (a montagem da pilha, a medida do potencial e seu emprego para o funcionamento de uma calculadora), conforme sequência de imagens mostradas na Figura 5. Há efeitos de aproximação (zoom) para destacar etapas da montagem. A tomada é frontal e a câmera está fixa (Figura 5A). Na demonstração do funcionamento dos equipamentos a câmera está na mão e posicionada na diagonal (Figura $5 \mathrm{C}$ ), também há aproximação para dar destaque ao funcionamento da calculadora (Figura 5D). Ao fim os estudantes destacam o uso de materiais simples e facilmente encontrados no dia-a-dia, com destaque que, além de funcionar para o experimento, o limão pode ser posteriormente consumido.

FIGURA 5 - Imagens das etapas de montagem da pilha e seu uso para o funcionamento da calculadora.

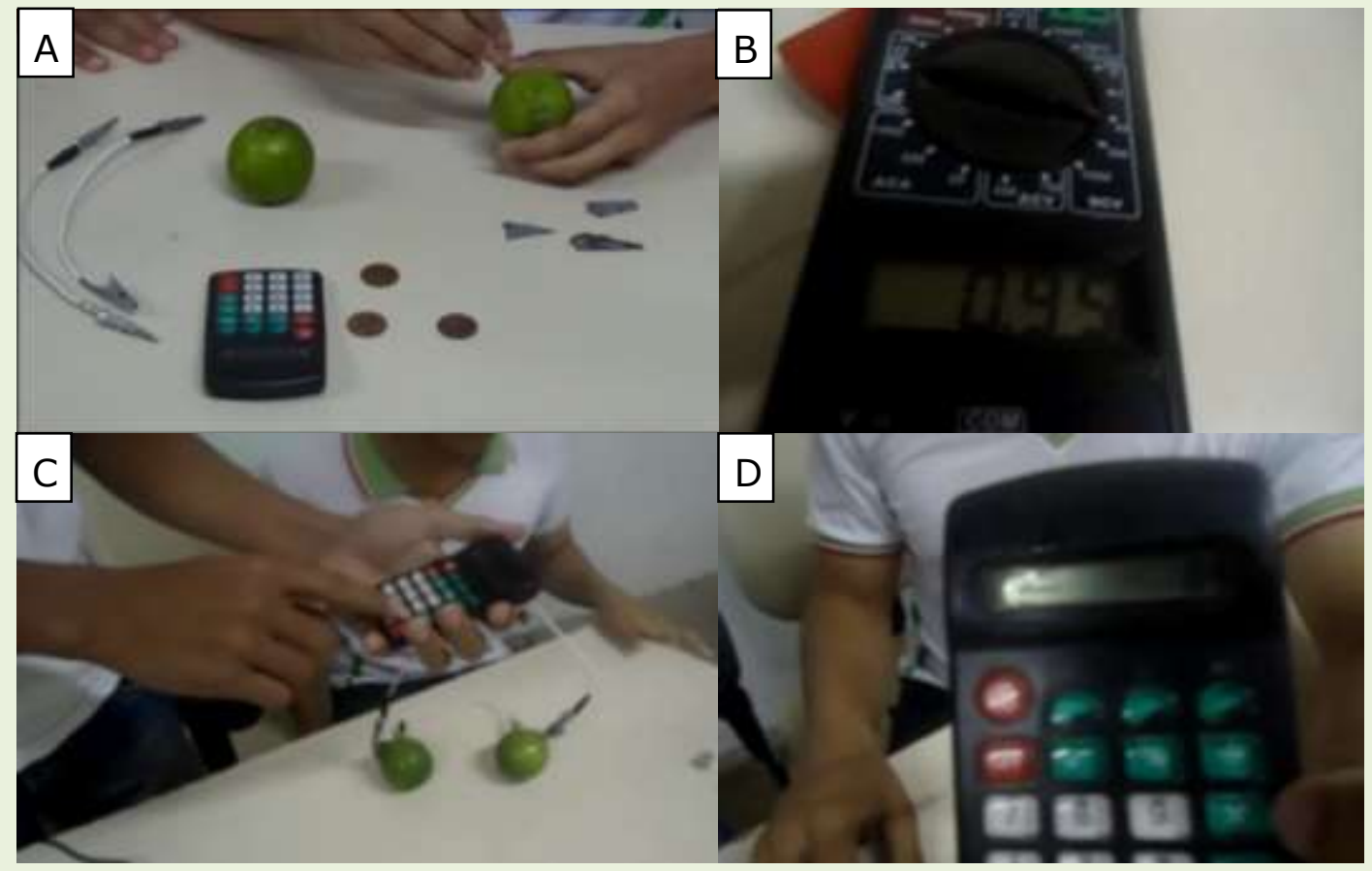

Fonte: Os autores. 
Embora o foco principal também pareça ter sido o experimento, notase ao mesmo tempo um tom de didatismo e de preocupação da relação da química com a vida diária, o que é explicitado nas respostas de 3 dos 4 estudantes componentes do grupo quando perguntados sobre o que acharam mais interessante no experimento.

\footnotetext{
"Gostei pois foi interessante ver que uma calculadora pode funcionar com um limão" (Aluno 1, grupo 4).

"Eu gostei por que é fácil de encontrar os materiais" (Aluno 2, grupo 4).
}

Ainda que o vídeo seja uma atividade avaliativa, por isso a preocupação de execução do experimento com sucesso, a mensagem principal também parece estar associada à possibilidade de utilizar materiais simples. Um tom de humor emerge durante algumas falas, como no momento de desfecho: "E no final (...) ainda pode aproveitar [o limão] para fazer um suco. E sempre que sua pilha acabar pode fazer essa experiência".

O endereçamento deste vídeo também parece ser a professora e outros estudantes de mesma faixa etária. Tais aspectos são evidenciados pela narração, que destaca o fato de ser um trabalho (escolar), além de ser sempre dirigida a um coletivo: "Bom pessoal, nós iremos fazer um trabalho de óxido-redução"; "Esse é um voltímetro para vocês que não sabem"; "É isso aí pessoal. Até a próxima".

Tanto o vídeo da pilha de limão quanto dos fantoches trazem à tona questões acerca do ensino de química. Um dos mais marcantes e que compõem o significado preferencial concerne à possibilidade do uso de materiais alternativos para a experimentação. Outros estudos de produção de vídeos por estudantes também destacam a relação entre a atividade experimental produzida em vídeo e sua aplicação no dia-a-dia, acenando a contribuição para o engajamento dos estudantes e para a criatividade (PEREIRA; BARROS, 2010; PEREIRA et al 2011).

Segundo Freire (2008), o apoio ao desenvolvimento da capacidade crítica do educando e à sua curiosidade implica respeito e estímulo também 
à espontaneidade de ação, sem a qual a criatividade pode ser sacrificada. Como já presente nos demais vídeos, nota-se uma interrelação entre criatividade e liberdade de ação no desenvolvimento dos vídeos amadores que está intrincada ao caráter lúdico da atividade.

Outra dimensão do vídeo "Construção de uma pilha de limão" referese à possibilidade de debate do pensamento científico. Para efetuar a medida do potencial voltaico em série, bem como em seu uso para o funcionamento da calculadora, os polos da pilha foram conectados de maneira invertida, resultando em um funcionamento inadequado do sistema. Ao verificar o não funcionamento, houve a correção da conexão pelo estudante.

A despeito de parecer um equívoco simples, o mesmo erro ocorreu por duas vezes, caracterizando um processo experimental calcado pela tentativa e erro, em detrimento ao pensamento hipotético-dedutivo que marca a ciência mais contemporânea. O pensamento hipotético-dedutivo possibilita que os sujeitos sejam capazes de utilizar o conhecimento para previsões a respeito do que pode ocorrer, ainda que tais previsões possam não se confirmar. Também permite (re)interpretar novas situações. Nessa direção, sob um viés pedagógico, o erro planta o inesperado e pode fomentar reflexões que não ocorreriam. $O$ erro no experimento fomentaria $o$ pensamento para a problematização das razões de acerto, bem como as possíveis causas de erro.

No vídeo "Produção de aluminato de sódio e hidrogênio" foi apresentado um experimento da reação entre hidróxido de sódio aquoso e alumínio metálico empregando-se uma latinha de refrigerante como recipiente (Figura 6). 
FIGURA 6 - Imagens do uso de uma latinha de alumínio como recipiente (procedimento) e seu estado final (após a reação).
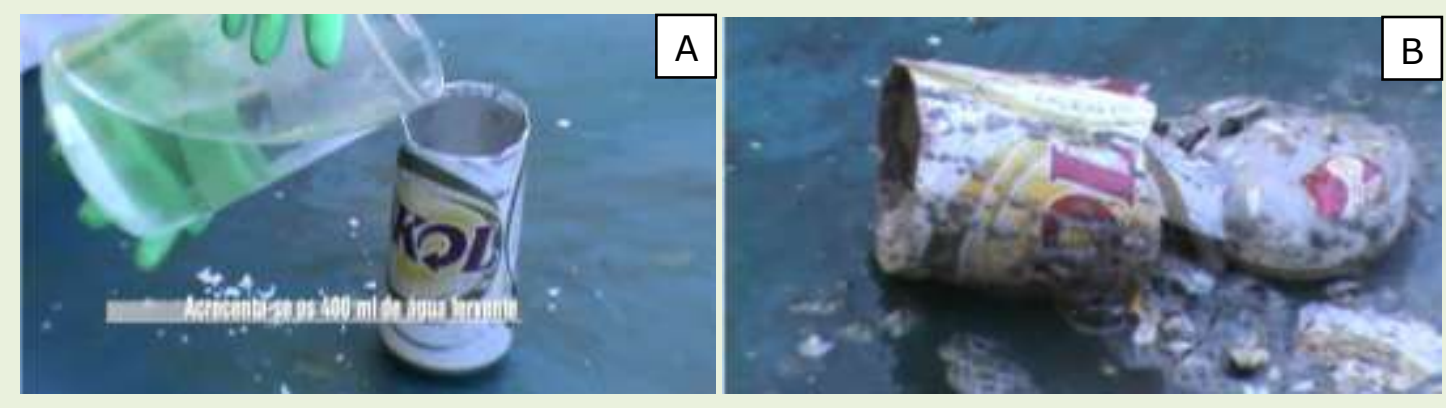

Fonte: Os autores.

A câmera foi localizada frontalmente e a aproximação de escala foi realizada para captar imagens mais detalhadas. A imagem volta ao enquadramento original para a execução do experimento, cuja descrição é conduzida simultaneamente por meio de legendas. $O$ vídeo seguiu com a apresentação das alterações ocorridas e sua interpretação sob o ponto de vista químico.

Em relação ao áudio, o vídeo teve fundo musical em toda a sua duração (música da banda Coldplay, chamada "Viva la vida"). O experimento foi apresentado por um componente do grupo, sendo conduzido em cima de uma mesa (em ambiente doméstico). Também foi possível observar preocupação com a segurança, pois quem realizou o experimento estava usando jaleco e luvas.

Este vídeo se diferencia dos demais por não apresentar características de humor. O curto tempo de duração e o foco na dimensão prática permite interpretar que a preocupação central está em mostrar o experimento, cujo destinatário principal seria a professora, uma vez que o vídeo consistia de uma atividade avaliativa. A preocupação em explicitar que se tratava de uma reação de oxidação-redução é evidenciada por legendas. A escolha de um experimento envolvendo explosão pode remeter à atração estética que este tipo de reação provoca nos jovens, uma visão de química geralmente associada a reações espetaculares tais como explosões, ideias muitas vezes reforçada pelos meios de comunicação. De fato, a escolha 
deste experimento pelo grupo foi pautada no efeito produzido na latinha de alumínio (Figura 6B), como revelou um dos estudantes por meio do questionário.

\begin{abstract}
"Esse experimento foi bastante interessante, pois todos do grupo ficaram impressionado com o estado que a lata ficava com a reação com a soda cáustica" (Aluno 2, grupo 1).

"Primeiro, vamos pegar a soda cáustica e colocar na água e deixar ela diluir. Segundo, vamos pegar o permanganato de potássio já diluído em água e vamos acrescentar."
\end{abstract}

Também pode ser notada na fala de um estudantes uma confusão conceitual entre os conceitos de dissolução e diluição. De uma maneira geral, houve dificuldade e uma tendência natural pelo uso de vocábulos mais próximos do dia-a-dia em detrimento aos termos e expressões científicas específicas da química, isso porque as pessoas não têm necessidade de refletirem a todo o momento sobre o que vão dizer. Por sua vez, a linguagem científica exige uma reflexão consciente no seu uso (MORTIMER, 1999).

É possível observar, portanto, problemas de apropriação de conceitos em algumas passagens. Ao mesmo tempo, a liberdade para que empregassem sua própria linguagem é uma das características lúdicas, discutida posteriormente. Para Freire, a relação entre a linguagem cotidiana e científica é dialética, não havendo separação entre as duas. Para além, o autor pontua um cuidado (FREIRE; SHOR, 2008, p. 131):

(...) nossa experiência na universidade tende a nos formar à distância da realidade concreta. Os conceitos que estudamos na universidade podem trabalhar no sentido de nos separar da realidade concreta à qual supostamente se referem (...). Assim, nossa linguagem corre o risco de perder o contato com o concreto. Quanto mais somos assim, mais distante estamos da massa das pessoas, cuja linguagem, pelo contrário, é absolutamente ligada ao concreto.

Ao trazerem a sua linguagem para $\circ$ vídeo, os estudantes trazem também a possibilidade para que o professor confronte-a com a linguagem científica. Isso pode mostrar a complementaridade dessas duas maneiras de 
conhecer o mundo, bem como suas parcialidades e dinamismos. Daí a importância dos vídeos produzidos enquanto momento dialético entre a linguagem cotidiana, irrefletida e concreta e a linguagem científica, refletida e abstrata.

Além disso, destaca-se que muitas vezes os alunos não conseguem relacionar o assunto estudado com os fenômenos vivenciados em sua vida cotidiana. Por meio da construção dos experimentos produzidos é possível explorar essa relação. Pereira et al (2011) também destacam a relação entre a atividade experimental produzida em vídeo e sua aplicação cotidiana, acenando para o engajamento dos estudantes e a criatividade. Em termos gerais, isso é possível porque os vídeos produzidos não encerram uma estrutura fixa ou pré-determinada, o que dá margem à liberdade de produção e à criatividade.

De maneira geral, em todos os vídeos destaca-se a presença espontânea de técnicas e elementos estéticos variados de produção (música, dramatização, humor, esquemas etc) que não se fazem presentes nas atividades experimentais clássicas, como reportam estudos similares (PEREIRA; BARROS, 2010; PEREIRA; REZENDE-FILHO, 2013). A escolha dos ambientes de filmagem foi provavelmente influenciada pelo contexto de produção e baliza o significado preferencial e o endereçamento dos autores. Isto é, o uso dos fantoches, por exemplo, não é meramente uma forma estética escolhida para os estudantes apresentarem o vídeo. $O$ fantoche, como instrumento de interpretação e brincadeira, também mantém relação com a necessidade que tais estudantes veem em tornar a química algo lúdico. Por sua vez, as notícias do jornal, as quais remetiam aos problemas enfrentados no dia-a-dia dos estudantes, compõem um cenário crítico no qual expressam sua leitura-de-mundo, encontrando no vídeo uma forma de vazão aos seus anseios. Ao mesmo tempo, a escolha pelos materiais de fácil acesso em todos os experimentos apresentados, bem como o destaque dado a tal aspecto durante os vídeos reiteram a necessidade de aproximação da química com o cotidiano. 
Os resultados mostram que a produção dos vídeos não é algo transparente e simples (PEREIRA; REZENDE-FILHO, 2013). Embora à primeira vista o produto pareça simples, em função de seu caráter amador, a mensagem, o endereçamento e os sentidos engendrados são influenciados pelos meandros da produção, incluindo aspectos sociais, estéticos e concepções sobre o ensino da química.

Tal atividade permite, pela sua natureza, liberdade de agir no desenvolvimento, estimulando a criação e conferindo prazer às ações empreendidas, características estas importantes à ludicidade (DOHME, 2003). Ressalta-se a interrelação entre o produto e o processo de sua construção, cuja liberdade de expressão para a escolha do experimento a ser realizado e de sua forma de apresentação no vídeo permitiram diversão e uma linguagem de aproximação ao cotidiano. Essa alusão às características lúdicas esteve presente nas respostas de 12 dos 19 estudantes quando indagados sobre o que gostaram na produção audiovisual.

"Divertido de fazer" (Aluno 1, grupo 2).

"Foi muito engraçado e divertido" (Aluno 1, grupo 3).

"Foi mais engraçado de gravar e bastante divertido e os experimentos bastante interessantes" (Aluno 2, grupo 3).

"Gostei muito da criatividade, destacando lógico o fato do incentivar o aprendizado dos alunos, uma vez que tornou-se uma atividade divertida e educativa" (Aluno 4, grupo 2).

"Gostei muito, foi mais engraçado de gravar e bastante divertido e os experimentos bastante interessantes, as reações químicas ocorrem frequentemente em nosso cotidiano e não nos damos conta" (Aluno 3, grupo3).

Tais resultados permitem inferir que o prazer propiciado pela criação e produção do vídeo é um elemento de destaque. Nesse sentido, a produção dos vídeos assume características lúdicas que contribuem para 0 engajamento na atividade. Isso pode ser atribuído à interação dos sujeitos 
com o novo. Para Chateau (1987, p. 33), o jogo para o adulto pode estar vivo e claro no que se pode chamar de "interação lúdica com o novo".

Além do prazer, a seriedade imposta à tarefa em função do engajamento em sua produção foi outro fator determinante. A questão da seriedade é muitas vezes posta de lado na atividade lúdica, mas é fundamental, conforme acena Chateau (1987, p. 124): "Jogar é, quase sempre, dar-se uma tarefa a cumprir, é cansar-se, e se esforçar para cumprila. O jogo é prova, repetimos, sempre; e, porque prova, é necessário que seja um programa da prova a se submeter".

Tal questão está diretamente associada ao prazer proporcionado pela atividade lúdica, prazer este decorrente da ação, cuja resposta ao desafio depende e implica no envolvimento dos sujeitos. De tal maneira, não é o jogo o atrativo em si, mas as ações e reações decorrentes da prova a que estão submetidos os jogadores. Desse modo, se faz importante a inserção de atividades que possam conduzir os estudantes a ações e reações.

Com muita frequência se tem pensado que a escola deve, como o jogo, ser atraente, e tem-se enganado quando ao significado desse termo. (...). A busca do atrativo é muito perigosa. Parte-se desse princípio correto - que os jogos atestam - de que a criança faz bem aquilo que faz com prazer, como, aliás, o adulto também. Princípio excelente, mas muito abrangente. Inspirando-se nele sem precisar o gênero de atrativo, não se apoia nem mesmo no jogo, já que há outros atrativos além do lúdico (...). O atrativo do jogo é superior (CHATEAU, 1987, p. 127).

Tal superioridade faz-se justamente na capacidade do jogo ser tarefa, ser desafio e, porque desafio, estimulante sob o ponto de vista de cognitivo. Prosseguindo com Chateau:

Quem diz jogo, diz ao mesmo tempo esforço e liberdade, e uma educação pelo jogo deve ser fonte de dificuldade física da mesma forma maneira que alegria moral. Repetimos (...), jogar é buscar um prazer moral. É esse prazer moral que devemos transpor para nossa educação (...). Por isso, é preciso apresentar à criança obstáculos a transpor, e obstáculos que ela queira transpor (CHATEAU, 1987, p. 128).

Nota-se, portanto, uma relação direta entre criatividade e liberdade no desenvolvimento dos vídeos amadores que está intrincada ao caráter 
lúdico da atividade. A produção corresponde a um momento de envolvimento cognitivo dos sujeitos, no qual curiosidade, criatividade e liberdade de ação são fundamentais para que a curiosidade assuma sua dimensão epistemológica. Estas se relacionam diretamente com o envolvimento dos sujeitos e são características definidoras de uma ação lúdica. Para produzir o conhecimento é indispensável que o sujeito esteja disposto a aprender, a engajar-se, e o processo de criação dos vídeos parece empreender tal função.

\section{CONSIDERAÇÕES FINAIS}

A partir dos resultados, dois elementos podem ser destacados no que tange à contribuição da produção de vídeos em aulas de química. O primeiro se refere às características de ludicidade observadas, especialmente a diversão, a liberdade, a criatividade e a responsabilidade. A produção do vídeo proporcionou aos alunos um maior envolvimento com o conhecimento químico, justamente em função dessas características lúdicas, possibilitando atuarem ativamente como sujeitos participativos, desde a construção do material até a apresentação deste para a turma e sua discussão. Outros trabalhos (PEREIRA; BARROS, 2010; PEREIRA; REZENDEFILHO, 2013) já haviam destacado a emergência de características similares, corroborando que os aspectos lúdicos se configuram como um dos elementos centrais na produção audiovisual. Nesse contexto, a relação entre criatividade e liberdade parece ser um aspecto central.

No entanto, como em qualquer atividade experimental, a execução e gravação do experimento não conduzirá diretamente ao maior desenvolvimento da aprendizagem conceitual dos estudantes, o que depende de fatores específicos da ciência química, tais como o estabelecimento de relações causais e conceituais, a linguagem, bem como o emprego dos modelos e teorias. Tais elementos não podem ser postos de lado e devem se constituir em pontos de discussão no momento da produção e durante a exibição dos vídeos. De tal maneira, emerge outro 
elemento útil ao pensar a produção de vídeos como estratégia pedagógica, a possibilidade avaliativa.

Em outras palavras, é possível avaliar e produzir aprendizagens nos momentos que permeiam todo o processo de produção, bem como de pósprodução (durante a socialização dos materiais). Torna-se imprescindível, neste contexto, a etapa de pós-produção em que professor e estudantes discutem os vídeos tanto sob os aspectos conceituais quanto culturais. Assim, a interação e o envolvimento proporcionado durante a produção possibilitam ao professor promover a discussão do conhecimento científico, tornando a análise e discussão dos vídeos um momento de ampliação do conhecimento. Tal aspecto merece atenção em investigações futuras, em que a discussão dos vídeos podem ser videogravadas e analisadas em termos das interações discursivas e apropriação da linguagem científica.

\section{REFERÊNCIAS}

BARDIN, L. Análise de Conteúdo. Lisboa: Edições 70, 2006.

CHATEAU, J. O jogo e a criança. São Paulo: Summus, 1987.

DOHME, V. Atividades lúdicas na educação: o caminho de tijolos amarelos do aprendizado. Petrópolis: Vozes, 2003.

ELLSWORTH, E. Modos de endereçamento: uma coisa de cinema; uma coisa de educação também. Em: T. T. Silva (Ed.), Nunca fomos humanos - nos rastros do sujeito (pp.7-76). Belo Horizonte: Autêntica, 2001.

FRANCISCO JUNIOR, W. E. Digital Videos of Experiments Produced by Students: Learning Possibilities. Em: K. Hahl; K. Juuti; J. Lampiselkä; A. Uitto; J. Lavonen (Org.). Cognitive and Affective Aspects in Science Education Research. (pp.141-153). Gewerbestrasse: Springer International Publishing AG, 2017.

FREIRE, P. Professora sim tia não: cartas a quem ousa ensinar. 19. ed. São Paulo: Olho d'água, 2008.

FREIRE, P. Pedagogia da autonomia: saberes necessários à prática educativa. 39. ed. Rio de Janeiro: Paz e Terra, 2009.

FREIRE, P.; SHOR, I. Medo e ousadia: cotidiano do professor. 12. ed. São Paulo: Paz e Terra, 2008.

FERRÉS, J. Vídeo e Educação. 2. ed. Trad. J. A. Llorens. Porto Alegre: Artes Médicas, 1996. 
HODSON, D. Hacia un enfoque más crítico del trabajo de laboratorio. Enseñanza de las Ciencias, v. 12, n. 3, 299-313, 1994.

HOFSTEIN, A.; NAVON, O.; KIPNIS, M.; NAAMAN-MAMLOK, R. Developing student' ability to ask more and better questions resulting from inquiry-type chemistry laboratories. Journal of Research in Science Teaching, v. 42, n. 7 , 791-806, 2005.

LICHTER, J. Using YouTube as a platform for teaching and learning solubility rules. Journal of Chemical Education, v. 89, n. 9, 1133-1137, 2012.

MORAN, J. M.; MASETTO, M. T.; BEHERENS, M. A. Novas tecnologias e mediação pedagógica. 21. ed. Campinas: Papirus, 2013.

MORTIMER, E. F. Sobre chamas e cristais: a linguagem cotidiana, a linguagem científica e o ensino de ciências. Em: A. CHASSOT A. e R. J. OLIVEIRA (Eds.), Ciência, Ética e Cultura na Educação (pp.99-118). São Leopoldo: Editora Unisinos, 1999.

MORTIMER, E. F.; SCOTT, P. H. Meaning making in secondary science classroom. Maidenhead: Open University Press/McGraw Hill, 2003.

PEREIRA, M. V.; BARROS, S. S. Análise da produção de vídeos por estudantes como uma estratégia alternativa de laboratório de física no Ensino Médio. Revista Brasileira de Ensino de Física, v. 32, n. 4, 4401-4408, 2010.

PEREIRA, M. V., BARROS, S. S., REZENDE FILHO, L. A.; FAUTH, L. H. A. Demonstrações experimentais de Física em formato audiovisual produzidas por alunos do ensino médio. Caderno Brasileiro de Ensino de Física, v. 28, n. 3, 676-692, 2011.

PEREIRA, M. V.; REZENDE FILHO, L. A. C. Investigando a produção de vídeos por estudantes de ensino médio no contexto do laboratório de física. Revista Tecnologias na Educação, v. 5, n. 8, 1-12, 2013.

SOARES, M. H. F. B. Jogos e atividades lúdicas para o ensino de química. Goiânia-GO: Kelps, 2013.

VANOYE, F.; GOLIOT-LÉTÉ, A. Ensaio sobre a análise fílmica. $5^{a}$ ed. Campinas: Papirus, 2008.

YIN, R. K. Estudo de caso: planejamento e métodos. Porto Alegre: Bookman, 1984.

Recebido em: Julho de 2017 Aprovado em: Março de 2018 